\title{
O Brasil no Espectro de uma Guerra Híbrida
}

\author{
Brazil on the spectrum of a Hybrid Warfare
}

\section{Sayd Mansur}

É doutorando em Comunicação e Cultura pela ECO-UFRJ (Tecnologias da Comunicação e Estética), mestre em Estudos Contemporâneos da Arte pela UFF, graduado em Estudos de Mídia também pela UFF (2013), e Cinema e Audiovisual pela Universidade Estácio de Sá (2007). Tem experiência na área de Comunicação e Artes, com ênfase em Novas Tecnologias, Estética e Filosofia.

\section{RESUMO}

O último livro do antropólogo Piero Leirner se dedica à análise do fenômeno das guerras híbridas, tendo como princípio a desnaturalização da ideia do Estado como máquina de domesticação da guerra. No livro o autor demonstra como as batalhas invadem o campo da política, não por ser uma anomalia desta, mas por estarem umbilicalmente atreladas. A partir disto, o etnólogo, pioneiro no estudo de campo entre militares, investiga como a participação das Forças Armadas nos bastidores na política brasileira, seria a causa e não a consequência da supracitada "polarização" política do presente.

PALAVRAS-CHAVE: guerra híbrida, etnologia, antropologia, antropologia política, Brasil

"Se a política intervém no que em princípio seria a guerra absoluta, é porque ela em algum ponto compartilha da mesma natureza, e de outra maneira não seria possível qualquer continuação entre uma e outra."

\section{Metafísica do poder}

Há uma antiga maldição chinesa que contempla seu destinatário com uma maliciosa ironia, ela conjura o desejo de que seu interlocutor viva em "tempos interessantes". Estar vivendo em tempos interessantes é definitivamente a certeza

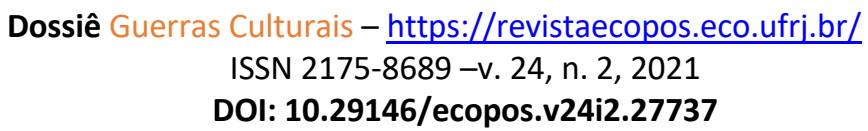


que se tem ao ler o recente trabalho de Piero Leirner, "O Brasil no espectro de uma guerra híbrida: militares, operações psicológicas e política em uma perspectiva etnológica". Lançado em 2020, o livro se debruça sobre o presente conturbado do Brasil, país que tem tido seu espectro político mobilizado a partir de uma esquemática "polarização", onde estátuas da liberdade se instalaram em pequenas cidades do interior do país e powerpoints rudimentares se interpõem no caminho de eleições diretas. Porém, o dado novo que Leirner trás, não são os relatos de práticas militares desconhecidas por nós, mas a compreensão de como esse panorama é sustentado por uma doutrina de defesa que hoje se volta para dentro, debilitando a distinção usual entre militares e sociedade, exterior e interior, guerra e política, conflito ou paz. A partir de análises, muitas vezes amplamente noticiadas nos últimos anos, resta a confirmação ante as suspeitas de que práticas de guerra refinadíssimas estão sendo aplicadas neste momento de maneira velada sobre nosso todo o território brasileiro.

Parte da desenvoltura com que o antropólogo nos apresenta sua leitura sobre os desdobramentos políticos das últimas três décadas, se dá pela experiencia acumulada no estudo de campo com os militares ainda nos primeiros anos de abertura política, quando desenvolveu uma dissertação pioneira sobre a hierarquia militar, a partir de uma imersão no ambiente das escolas militares, num momento especialmente propício, que marcou a reorientação de nossa doutrina de guerra com o fim definitivo da União Soviética. Aliás, um contexto bem diferente do atual, onde nossos militares têm se manifestado sistematicamente contra as instituições democráticas, dando inclusive declarações sazonais em descrédito à lisura de nossas eleições, gesto que teria como única finalidade respaldar as premissas infundadas com que o Executivo tem mobilizado suas bases.

Leirner nos apresenta uma leitura detalhada de fatos, que ilustram como se ampliaram as fissuras entre os militares e os governos civis de FHC à Dilma Rousseff. O desenrolar deste litígio, inicialmente com fortes indícios de unilateralidade, todos

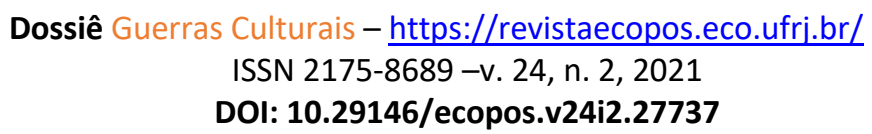


sabemos como termina; na eleição de 2018 e na participação ativa dos militares em áreas estratégicas do governo, numa proporção em número superior ao auge da ditadura que travessou três décadas.

Todo caso, ainda que esta "primeira fase" tenha se encerrado, estaríamos muito longe de um término, mas sim num aquecimento para o acirramento do conflito com a proximidade das eleições de 2022. Afinal, parte essencial do que define uma "guerra híbrida" é a arquitetura de todo um teatro de operações e infiltrações que se voltam para dentro e não para fora, diferente do que imaginamos quando pensamos na direção das forças de Defesa de qualquer nação. A disputa por território há muito deixou de ser externa para ser interna, e mais delicado que isso, a disputa por territórios sobre as mentes e corações de sua própria população.

A abordagem da guerra híbrida consiste no disparo de operações psicológicas (ou "Op Psi” no jargão militar), onde se permite que atores sociais operem a seu favor, replicando informações e visões de mundo desejadas pelo campo inimigo, de modo que seja perpetuada uma abordagem indireta que encobriria a informação fundamental, a de que um conflito está em curso avançado. Esta dinâmica, envolveria mais a construção de uma hegemonia em sua imposição de valores e símbolos, do que o visível aparelhamento do Estado que tem sido orquestrado pelo atual governo. É o que se percebe quando a continência extrapola os limites do quartel, aponta Leirner.

\section{Revoluções coloridas}

No quadro político contemporâneo, há um consenso de que as estratégias para implementação e amparo de um guerras hibridas foram pensadas no mundo a partir da mudança na doutrina militar dos EUA durante e após os conflitos do Iraque e Afeganistão. Antes disto, há relatos creditados pelo próprio governo norteamericano, de que há traços de uma guerra híbrida na Eurásia ainda no final dos anos noventa orientada pela Rússia, que por sua vez acusa o EUA das mesmas

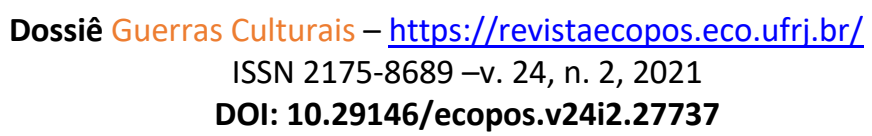


práticas nos conflitos em que se envolveu na Geórgia e na Ucrânia. Ou seja, a troca de acusações entre as duas maiores potências militares apenas confirma que esta modalidade de conflito não é uma novidade ou fantasia, mas uma realidade há mais tempo do que podíamos imaginar.

Para uma melhor compreensão, precisamos ter em vista que no universo militar há um princípio basilar: a delimitação num dado contexto quanto às posições amigas e inimigas. É a partir desta compreensão que teremos uma adesão automática às posições amigas e a compreensão do desenho de forças e hierarquia inimiga. No Brasil a guerra híbrida teria um componente inédito, ela teria se dado no interior de nosso núcleo militar, depois se espalhando, para em seguida tentar unificar sua população, algo que ainda está em suspendo. Esta especificidade do caso brasileiro, explicaria a diferença da sequência de "revoluções coloridas" ou "primaveras árabes" que partiram de pautas identitárias. Aqui, as coisas teriam aconteceram ao inverso, com o próprio governo sendo acusado de estar criando dissonância e divisão na sociedade a partir do "identitarismo".

Todo caso, longe de encapsular 2013 como parte de uma maquinação internacional, Leirner compreende que estes movimentos nasceram de uma inquietação coletiva e espontânea, mas que teriam sido cooptadas pela prática da cismogênese. A cismogenese é um processo de diferenciação nas normas de comportamento individual resultante da interação acumulativa dos indivíduos em uma sociedade. 0 termo ganhou a luz em "Naven", trabalho etnológico de Gregory Bateson, lançado em 1936 sobre uma tribo da Nova Guiné. Seu princípio consiste em considerar as ações de A ao comportamento de B, percebendo como essas reações alteram o posterior comportamento de B e em seguida seus efeitos em cadeia sobre A. Com origem no grego (sua tradução literal seria algo como "criação de divisão"), ela seria um mecanismo para atuar sobre tendencias de mudanças em grupos de indivíduos.

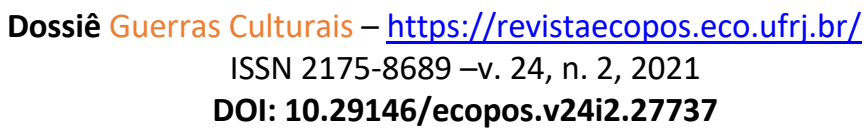


Se, por exemplo, um dos padrões de comportamento cultural, considerado apropriado no indivíduo A, é culturalmente rotulado de padrão assertivo, enquanto de $B$ se espera que responda isso com o que é culturalmente visto como submissão, é provável que esta submissão encoraje uma nova asserção, e que essa asserção vá requerer ainda mais submissão. Temos então um estado de coisas potencialmente progressivo, e, a não ser que os outros fatores estejam presentes para controlar os excessos de comportamento assertivos ou submissos, A precisará necessariamente se tornar mais e mais assertivo, e B se tornará mais e mais submisso; essa mudança progressiva ocorrerá, sejam A e B indivíduos separados ou membros de grupos complementares. (Leirner, 2020, p.176 e 177)

Este processo que se dá entre sujeitos, engendraria de um A para um B, com B uma vez "capturado", disposto a replicar os conceitos, as memórias e as direções orientadas por A, estratégia que leva a participação do próprio cativo na reprodução de imagens que irão subjugar seu povo. Essa estratégia viria hoje através de uma abordagem indireta, onde a cabeça por trás destas práticas agiria nos bastidores, em segurança, enquanto os subordinados, ou os passivos sujeitos "B" instituiriam "fábricas de consenso", disseminando notícias e análises fabricadas artificialmente de modo a dar a oportunidade que estes eventos sejam "conectados" pelo receptor. Ou seja, a maximização dos resultados nessa guerra de informações vem somente quando o receptor "liga os pontos" e chega à uma conclusão deixada implícita por sua própria conta. Em verdade, é exatamente isso o que o próprio autor faz conosco quando implicitamente deixa para o leitor uma pergunta latente ao longo de todo o livro, seriam os nossos militares o sujeito $B$, que aterrorizado por uma ameaça ao qual foi treinado anos para combater, em sua submissão e alinhamento automático ao sujeito A, estaria reproduzindo sobre sua própria população as táticas desta guerra? Afinal, não teria sido este o legado natural de 40 anos de uma "guerra fria"?

É de conhecimento geral como muitos no alto escalão de nossas Forças Armadas enxergam no Partido dos Trabalhadores, o início de uma guerra híbrida

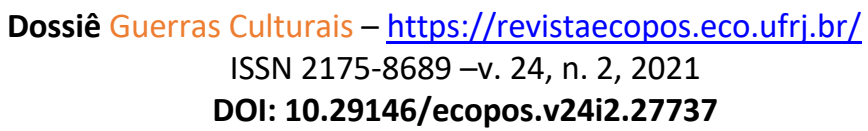


pela doutrinação cultural gramsciana, deste modo teria ocorrido seu contra-ataque em função das disrupções provocadas pelo que consideram ser o inimigo, personagem pertencente a um espectro cada vez mais amplo dentro das ditas esquerdas. Trata-se claramente da propagação de um jogo de informações e contrainformações que desestabilizam os poderes constituídos, reorganizando posteriormente as forças sociais a partir de um segundo movimento de ordenação cognitiva que se dá dentro de um jogo institucional que aparenta normalidade tanto da Justiça, como da Imprensa e sociedade civil. Com as "Op Psi" (ou "Opsi") visando à obtenção de vantagens militares sem o uso da força e com a propaganda sendo empregada em associação com outras medidas de caráter econômica e política, as fronteiras físicas cederam às fronteiras psicológicas, onde mais uma vez se repete a inserção de uma expertise norte-americana transferida à oficiais brasileiros. Agora, após uma virada ontológica, o aspecto político se não se sobrepõe às manobras geográficas, mas atua como complemento antecipatório às ações de infantaria.

\section{Infiltração e contrainformação}

Porém, distante de apontar a guerra híbrida como um método novo no campo das sociedades modernas, o autor defende que não há novidade alguma, mas que ela pode ser considerada como um desdobramento de elementos já existentes. Os EUA utilizam desde a guerra do Iraque e Afeganistão a participação de antropólogos e sociólogos, numa evolução da famosa experiencia da Inteligência norte americana perto do fim da Segunda Guerra, quando Ruth Benedict analisou os meandros para negociação da rendição japonesa. As análises de Benedict sobre o fatalismo, a vergonha, a autodisciplina e o sistema de obrigações japonês ficaram famosas no clássico "O Crisântemo e a Espada" de 1946. Indubitavelmente, parte do esforço de guerra sempre se baseou no entendimento de que é necessário encorajar o inimigo a fazer a escolha que você, enquanto adversário, prefere. Deste modo, temos claro

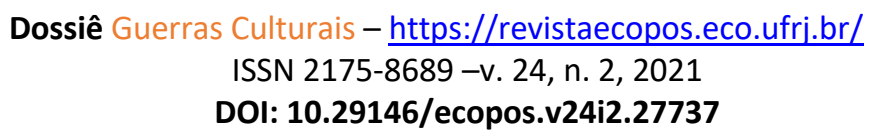


que a guerra nunca foi só sobre a aplicação da força física, mas da busca pelo controle metafísico.

Parte do esforço do autor, está em demonstrar que a diluição da fronteira entre guerra e política, que as guerras híbridas proporcionam é um antagonismo que provavelmente nunca existiu, mas apenas postulado em bases teóricas jamais aplicadas. De modo que, em seu modo "híbrido" a guerra se aproximaria de vez das táticas terroristas e criminosas; por sua indistinção entre tempos de guerra e paz declarada, e alvos civis e militares, o que aliás não seria novidade, mas apenas uma convenção que nunca se realizou. A guerra hibrida acaba pondo em xeque a mitologia do Estado como divisor de águas entre a civilização e a barbárie, a partir da separação entre público e privado, ao qual estaria condicionada a violência externa entre os indivíduos. Prevalece a ideia de que a guerra sede lugar ao Leviatã, de que o Estado pacifica a sociabilidade e expulsa a guerra para fora. Todo caso é notório que esta domesticação não se fundamenta, pois, assim como o Estado age em seus próprios termos como antes agiam as casas e clãs, ele é capaz de dissimular suas intenções, apagando seus rastros e criando uma falsa coincidência entre público e político. Porém, ao desnaturalizar a ideia de que o Estado é uma máquina de domesticação da guerra, compreendemos que quando a guerra supostamente invade o campo da política, ela não o faz como uma anomalia, mas porque estas duas são atividades humanas umbilicalmente ligadas, e como lembra o autor, a política como extensão da guerra foi uma ideia no qual Michel Foucault insistiu de modo muito contundente em obras como "Em Defesa da Sociedade" e "O Nascimento da Biopolítica".

Neste contexto, é natural encontrarmos nas ciências políticas a compreensão de que pequenas falhas neste processo poderiam ocorrer em razão de pequenos golpes, crises e violência interna dos Estados. Indo mais fundo, Leirner questiona se as constantes intervenções e golpes militares sempre associadas a falhas políticas em democracias instáveis, ou "incompletas", não deveriam ser analisadas à luz da

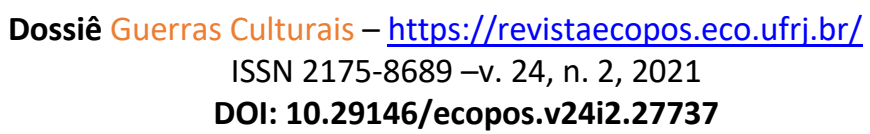


Guerra, ao invés da compreensão weberiana ${ }^{1}$ de que esta só viria à baila com a incompletude da política, como resquícios de sociedades tradicionais, como defeitos que tornam seu processo incompleto, sem considerar, no limite, sua lógica interna. Esta demarcação ontológica sustentaria toda a ideia do Estado como um polo regulador diante do caos, afinal, em sua ausência não teríamos garantias de retorno a um estado de truculência, pois, "quem, afinal, nunca ouviu falar que a 'ausência do Estado' é a causa da violência nas favelas, na Amazônia?" (Leirner, 2020, p. 113).

É a partir desta interpretação pragmática que acompanhamos a linha de tempo perversa onde se desenrola o fim do governo Dilma, que entre outras fatos, entrou em rota de colisão com o alto comando das Forças Armadas, à primeira vista, em razão da continuidade da Comissão da Verdade e Justiça (CNV), e da retirada da cúpula militar sobre a decisão final sobre progressões de carreira de militares. Esse choque, aliás, não deixa de ser observado em paralelo aos desencontros de outro expresidente, João Goulart, que em retrospecto, parece ter minimizado os riscos políticos de seus atos, fazendo muitas vezes o inverso do que aliados como Amaral Peixoto, Tancredo Neves e o capitão de mar-de-guerra Ivo Corseuil (chefe do Serviço Federal de Informações e Contrainformações), constantemente orientaram.

Entretanto, na análise dos fatos, jamais se credita ao governo de Rousseff a dianteira pelo desenrolar dos acontecimentos, pois, em verdade, a hipótese mais aventada continua sendo a de que o pré-sal tenha desencadeado todo esse imbróglio entre Defesa e Executivo, com parte das Forças Armadas empenhada em um injustificável desvio de função para concretizar o que consideram o "desaparelhamento" do PT sobre os preciosos recursos naturais do Brasil. Tem isso em vista, temos uma escalada de declarações que beiram à insubordinação, e se intensificam quando o governo Dilma delega ao Ministro da Defesa, e não mais aos

\footnotetext{
1 A premissa de Weber parte do entendimento de que a guerra precisa ser expulsa da sociedade para dialeticamente existir a emergência do Estado.
}

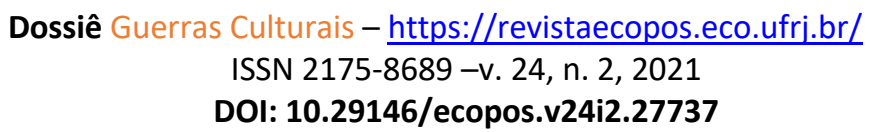


próprios militares, a edição de atos relativo a carreiras militares. À época, o Ministério era encabeçado por Jacques Wagner, e tinha como secretária Eva Chiavon, que o acompanhava desde que era governador na Bahia. De imediato, Eva foi vista com desconfiança entre os meios militares, basicamente por ser esposa de Francisco dal Chiavon, segundo nome na hierarquia do MST. A nomeação e ampliação dos poderes de Eva causava constrangimento, pois segundo os militares seu cargo foi ganhando atribuições, de modo que se criou uma barreira na hierarquia, quando antes os militares tinham um canal direto com o ministro da Defesa. Além disso, incomodava o fato de que a secretária de Defesa mantinha status semelhante ao do Chefe do Estado Maior das Forças Armadas. Esta situação pioraria com o decreto no 8.515 de 3 de setembro de 2015 (vésperas do 7 de setembro), que tirava dos comandantes das três Forças a palavra final sobre promoções, exonerações, transferências e nomeações de todo o círculo militar. Estas agora passariam a ser confirmadas por um cargo de indicação política.

A partir daí uma série de declarações desencontradas vieram de ambas as partes, com os militares alegando surpresa quanto ao decreto, e o executivo alegando surpresa quanto à reação negativa do que aparentemente já havia sido acordada entre os militares e a secretária de Defesa, ao mesmo tempo em que os Ministros Jacques Wagner e Aloizio Mercadante (Casa Civil) alegaram desconhecer o texto. Ainda que o governo tenha voltado atrás quanto ao decreto, o estrago havia sido feito. Outro ponto destacado em artigos que circularam entre os militares foi o estranhamento que os militares fizeram pela participação de Eva junto ao Conselho de Administração de Empresas Públicas, onde faria a ponte entre o Ministério da Defesa e as empresas admiradoras do pré-sal, para eles um dado que demarcaria as intenções do governo em lotear os recursos naturais para "inimigos" como China e Rússia. Na sequência, o dado que definitivamente azedou a relação entre o governo de Dilma Rousseff e as Forças Armadas veio no mês seguinte, quando um decreto do executivo praticamente extinguiu o GSI (Gabinete de Segurança Institucional), que

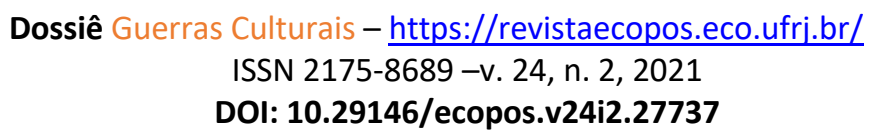


existia desde 1938, retirando-lhe o status de ministério e subordinando-o à Casa Civil.

Entre todas essas informações, talvez a mais importante seja a compreensão do papel de nossas Forças Armadas no comando da "Missão das Nações Unidas para a Estabilização no Haiti" (MINUSTAH), criada pelo Conselho de Segurança das Nações Unidas, e que agregou uma tropa composta por 22 que incluía de países das Américas como a Chile, México e EUA, à Croácia, Sri Lanka, Indonésia e Filipinas. Sua participação não se deu apenas na frente de batalha, mas no intuito de "pacificar" o país após de 2004 à 2017. Para além do fato de que muitos destes comandantes entenderam a operação como um combate à criminalidade comum, coube aos nossos militares:

Coordenar inúmeras agencias, ONGs, setores de administração, relações com as elites locais, com o Governo incipiente, elaborar eleições, cuidar de catástrofes naturais, promover alocação de recursos, administrar o "cenário psicossocial", além, é claro, de comandar uma tropa multinacional. (Leirner, 2020, p.234)

Hoje temos claro que a MINUSTAH serviu não apenas como laboratório para as recentes intervenções no estado do Rio de Janeiro, como foi uma experiencia limite entre a intervenção militar e a política. Aliás, foi neste período que o general da reserva Augusto Heleno diz ter aprendido a "vivenciar intensamente, em vários idiomas, todos os aspectos que cercam as atividades de Comunicação Social em uma situação de crise, envolvendo órgãos de imprensa motivados por diferentes interesses" (Heleno apud Leirner, 2020, p. 238)².

Aqui, é de extrema importância a compreensão prévia do autor sobre o universo militar em sua já referida experiência em pesquisa no ambiente da caserna.

\footnotetext{
2 "Entrevista: General Heleno: do Comando da Amazonia à comunicação do COB, por Mariângela Haswani”. Revista ALTERJOR Grupo de Estudos Altejor: Jornalismo Popular e Alternativo (ECA-USP), Ano 07, Volume, 01 Edição 13, Janeiro-Junho de 2016.
}

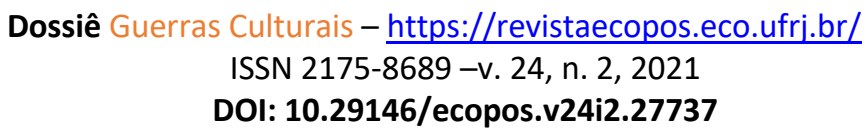


Leirner alerta sobre o círculo vicioso a que estamos presos, em primeiro lugar em razão do tabu hierárquico básico no militarismo, assim como pelo consequente caminho a que toda e qualquer informação estará condicionadas dentro deste sistema. Assim, a formação e visão acerca do mundo será intensificada por leituras direcionadas basicamente em função de resenhas e comentadores internos. Ou seja, toda a resistência anticomunista e leituras sobre o "marxismo cultural" ou conspiração gramsciana vem sendo a feita a partir de apostilas, resumos feitos por comentadores, justamente como uma "cola institucionalizada". É fácil imaginar o percurso ideológico de um cadete que após 40 anos se torna General, ele não esteve condicionado à novas informações, mas apenas recondicionando as primeiras ao qual foi inclusive obrigado a memorizar em seus primeiros anos de carreira. Somese isso ao fato de que há um certo ineditismo sobre registros em qualquer nação, ou período histórico, de um militar reconsiderando posições, conceitos ou práticas.

Mesmo em relação a informações puramente técnicas, há uma readequação à realidade para que caiba num propósito presente. Afinal, segundo o autor, as Universidades são frequentemente usadas como contraexemplo dos valores militares, como ambiente indomesticável e desritualizado. Outra instituição rival, apontada com naturalidade por nossos militares é o Itamaraty, tanto pela fronteira tênue que existe entre guerra e diplomacia, como pelo fato da carreira de um diplomata ser muito similar à de um militar, porém envolta em glamour e sem a dose de sacrifício que os últimos tendem a se auto atribuir.

\section{Presente}

Após o fim da União Soviética e sem um papel claro no atual tabuleiro, nossos militares ao que tudo indica depositaram na Amazônia todo o repertório de defesa num clima de guerra revolucionária, e inventaram uma tradição: a da cobiça internacional sobre a Amazônia. É claro, que esta visão diante de uma cobiça já vinha

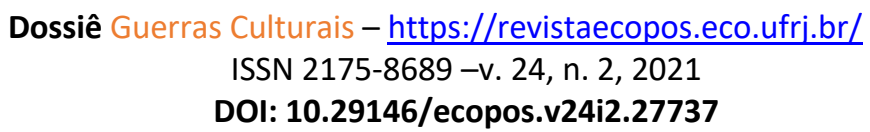


de antes, no regime militar onde se propagou o lema "integrar para não entregar", que insistia no destino "manifesto" do Brasil enquanto potência que detinha a vocação singular de nossa nação. É evidente que um facilitador desta ideia está no fato de que, desta vez as nossas forças armadas não estariam atuando em segundo plano contra um inimigo externo, nem mesmo atuando em um terreno secundário. Foi o que provavelmente o que direcionou a publicação de livros como o "A Farsa Ianomami", de Carlos Alberto Lima Menna Barreto, lançado em 1995, onde o autor busca sustentar a partir do que pretende ser um manual etnológico, político e militar que demonstraria uma manipulação internacional para impedir nosso desenvolvimento e fragmentar nosso território se utilizando de supostos ianomamis.

Com isso em mente, é preciso que o quanto antes a sociedade esteja atenta à diretriz que tem reconfigurado nosso cenário político construído a tão duras penas com a redemocratização. Hoje, percebe-se com mais clareza algumas das estratégias tem mobilizado nossa opinião pública, ainda que as investigações frente às irregularidades de 2018 mal tenham avançado na Justiça, quase quatro anos depois das últimas eleições. Um destes métodos utilizados à exaustão, é o do "policial bom, policial mal", algo típico em declarações do atual presidente, que logo em seguida são contemporizadas por seu vice.

Todo caso, é possível que um horizonte ainda seja percebido, afinal, quando observamos a autofagocitação dos outrora celebrados atores deste processo, o quadro geral é animador: empresas de comunicação e STF afrontados, Cunha preso, Temer preso (ainda que de volta à liberdade), Moro e Dallagnol em crescente descrédito, ao mesmo tempo em que Olavo de Carvalho retorna ao Brasil para tratamento no Sistema Único de Saúde. 
Referência Bibliográfica

LEIRNER, Piero C. O Brasil no espectro de uma guerra híbrida: militares, operações psicológicas e política em uma perspectiva etnográfica. São Paulo: Alameda, 2020.

Dossiê Guerras Culturais - https://revistaecopos.eco.ufri.br/

ISSN 2175-8689-v. 24, n. 2, 2021

DOI: 10.29146/ecopos.v24i2.27737 